Abstract

\title{
The Effect of (E,E)-2,4-Decadienal, (E)-2-Decenal, 2-Undecanone and Furfural on Reproduction of Tenebrio molitor ${ }^{+}$
}

\author{
Justyna Mirek, Karolina Walkowiak-Nowicka and Małgorzata Słocińska
}

Citation: Mirek, J.; Walkowiak-

Nowicka, K.; Słocińska, M. The effect of (E,E)-2,4-Decadienal, (E)-2-Decenal, 2-Undecanone and Furfural on Reproduction of Tenebrio molitor, in Proceedings of the 1st International Electronic Conference on Entomology, 1-15 July 2021, MDPI: Basel, Switzerland, doi:10.3390/IECE10540

Published: 1 July 2021

Publisher's Note: MDPI stays neutral with regard to jurisdictional claims in published maps and institutional affiliations.

Copyright: (c) 2021 by the authors. Submitted for possible open access publication under the terms and conditions of the Creative Commons Attribution (CC BY) license (http://creativecommons.org/licenses /by/4.0/).
Department of Animal Physiology and Developmental Biology, Adam Mickiewicz University, Poznan, Poland

* Correspondence: justynamirek11@gmail.com (J.M.); malgorzata.slocinska@amu.edu.pl (M.S.)

+ Presented at the 1st International Electronic Conference on Entomology (IECE 2021), 1-15 July 2021; Available online: https://iece.sciforum.net/.

Modern agriculture has numerous consequences, such as soil degradation, toxicants accumulation and toxicity for non-target organisms. For this reason, researchers refer to the discovery of harmless pest control tools as an alternative to synthetic insecticides. A solution might be a natural origin compounds such as plant-derived substances. Among them are plants secondary metabolites, which may be bioinsecticides, due to their biological activity like inhibition of food intake or insect growth and development.

Insects can produce many eggs, so oogenesis and oviposition could be the worthwhile aim of pest control. This study aimed to evaluate the influence of four plant metabolites: (E)-2-decenal, furfural, 2-undecanone and (E,E)-2-4-decadienal on ovarian development, taking into account the morphology of final oocytes, the number of eggs and larvae hatching the Tenebrio molitor beetle, a common storage pest. We used compounds in 2 concentrations: $10^{-5}$ and $10^{-7} \mathrm{M}$ injected into an adult females insect.

We showed a significant decrease in the volume of terminal oocytes after application of 2-undecanone at concentration $10^{-5} \mathrm{M}$ and an increase for (E,E)-2-4-decadienal and furfural treatment. In the lower concentration of chemicals, we noted a gentle drop in the volume of terminal oocytes only after (E)-2-decenal. In each case, follicle epithelium was well

developed. We observed a significant decrease in the number of laid eggs only for the 2undecanone in the lower concentration $10^{-7} \mathrm{M}$. In any other case, there were no significant changes. Moreover, the number of hatching larvae after application tested compounds in $10^{-5}$ and $10^{-7} \mathrm{M}$ dose was lower as an effect of lying unfertilized eggs by females.

Obtained results suggest a disturbing effect of tested compounds on pests reproduction. 